\title{
Patterns of larval Atlantic croaker ingress into Chesapeake Bay, USA
}

\author{
Jason J. Schaffler ${ }^{1, *}$, Christian S. Reiss ${ }^{2}$, Cynthia M. Jones ${ }^{1}$ \\ ${ }^{1}$ Center for Quantitative Fisheries Ecology, Old Dominion University, 800 W. 46th St., Norfolk, Virginia 23529, USA \\ ${ }^{2}$ NOAA, Antarctic Research Division, SWFSC, 8604 La Jolla Shores Dr., La Jolla, California 92037, USA
}

\begin{abstract}
We compared ingress patterns of Atlantic croaker Micropogonias undulatus larvae into Chesapeake Bay, USA, with published ingress patterns through barrier island inlets, the accepted model for larval fish ingress. This model asserts that larvae ingress on night flood tides at the flooddominated side of the inlet and at all depths. At the Chesapeake Bay mouth and in the adjacent coastal waters, we compared the distribution of abundance, size, age, and growth rates of croaker prior to ingress. In contrast to the barrier island inlet model, croaker larvae were more abundant at depth than closer to the surface regardless of location. However, the response to light was variable, where croaker larvae farther offshore showed no response to light, but croaker larvae in the bay mouth were more abundant at night. Croaker larvae followed an expected pattern of increasing age and length from offshore stations to the bay mouth station. Further, among nearshore coastal stations there was evidence of larger and older croaker larvae at the northern portion of the bay mouth than at middle or southern stations. Patterns in growth were similar at all locations, indicating the likelihood of a single source location or similar environments among transport pathways for croaker larvae. Ingress can occur across the entire mouth of Chesapeake Bay; however, net tidal inflow may result in age and size structuring, which allows more rapid movement into the northern flooddominated portions of the bay mouth.
\end{abstract}

KEY WORDS: Larval ingress · Atlantic croaker $\cdot$ Chesapeake Bay $\cdot$ Depth $\cdot$ Daily age Resale or republication not permitted without written consent of the publisher

\section{INTRODUCTION}

Recruitment of larval fishes from continental shelf waters to nearshore waters along the Mid- and SouthAtlantic Bights has been examined numerous times (Lewis \& Judy 1983, Pietrafesa \& Janowitz 1988, Epifanio \& Garvine 2001, Grothues et al. 2002). Most of these studies were concerned with the guild of offshore winterspawning fishes that reproduce over the mid- to outer continental shelf (Miller et al. 1984, Warlen \& Chester 1985). Among the species that make up this guild of fishes are several recreationally and commercially valuable fish species including Atlantic croaker Micropogonias undulatus (Diamond et al. 1999, Coleman et al. 2004).

After spawning, fish eggs and larvae are subjected to passive transport mechanisms that result in cross shelf transport towards bays and estuaries along the coast (Epi- fanio \& Garvine 2001, Bradbury et al. 2003). Cross shelf transport occurs at a relatively constant rate until larvae arrive in the nearshore waters of the coastal environment where onshore transport slows, often resulting in larval pooling (Nelson et al. 1977, Boehlert \& Mundy 1988, Hettler \& Hare 1998). Larvae pool in 2 general areas before estuarine recruitment. The first is nearshore accumulation, where larvae transition from continental shelf waters to areas that are influenced by nearshore processes (e.g. Chesapeake Bay plume; Reiss and McConaugha 1998). The second is accumulation near inlets or estuary mouths, which has been demonstrated for barrier island inlets (Boehlert \& Mundy 1988, Hettler \& Hare 1998).

Once larvae arrive near an inlet, estuary, or bay mouth, ingress can result from active mechanisms, such as selective tidal stream transport, to both enter and remain within the estuary (Boehlert \& Mundy 
1988, Forward \& Tankersley 2001, Hare et al. 2005). Alternatively, passive transport mechanisms, which result in transport/advection to the receiving waters, such as residual bottom inflow (Joyeux 1999, Schultz et al. 2003) and wind-driven transport (Shaw et al. 1985, Joyeux 1999), may also explain larval ingress into bays and estuaries. The actual mechanisms seem to be species and location specific and often are a combination of both active and passive mechanisms (Hare et al. 2005).

Most collections concerning larval fish ingress have been made at mid-channel stations in narrow tidal inlets such as Beaufort Inlet (e.g. Boehlert \& Mundy 1988, Hettler 1998, Joyeux 1998). Due to the Coriolis force, water currents in the northern hemisphere are deflected to the right, which has several consequences for tidal inlets. For example, net inflow (flood dominated) occurs at northern or eastern portions of the inlet depending on the orientation. Net outflow (ebb dominated) occurs at the southern or western portions of the inlet. The impacts of lateral position on patterns of ingress have been evaluated extensively in narrow barrier island inlets (Weinstein et al. 1980, Forward et al. 1998, 1999, Churchill et al. 1999b). There are increased densities of larval fish in the water entering via the flood-dominated portion of the inlet. Depth plays a lesser role than lateral position, largely because barrier island inlets are shallow and well mixed. In general, croaker larvae are found near the bottom during the entire tidal cycle (Raynie \& Shaw 1994, Joyeux 1998). However, larval abundances are much greater during the night than during daylight (Raynie \& Shaw 1994, Joyeux 1998, Forward \& Tankersley 2001).

In contrast to barrier island inlets, fewer ingress studies have been conducted in larger openings of drowned river valley estuaries such as Chesapeake Bay (Hare et al. 2005). In estuaries with large openings, tidal flows have increased lateral variability compared with more narrow inlets (Wong 1994, ValleLevinson \& Lwiza 1997, Kasai et al. 2000). In Chesapeake Bay, net outflow occurs at the southern portion of the bay mouth, and net inflow occurs at the northern portion. Therefore, we expect larval ingress to occur at a greater rate in the flood-dominated portion of the bay mouth. However, water movements at the mouth of Chesapeake Bay are much more complicated than those predicted by Coriolis effects alone (ValleLevinson \& Lwiza 1997). Influx of oceanic water occurs through channels at depth, while outflow occurs at the surface and over shoals. The effect of depth on larval ingress into systems that exhibit 2-layered flow is likely to increase relative to well mixed inlets. Therefore, we also predict that larval abundance should be greater at depth than at the surface (Fortier \& Leggett 1983, Laprise \& Dodson 1989, Rowe \& Epifanio 1994,
Hare \& Govoni 2005). Less is known about the effects of light on larval ingress into deeper estuaries; however, catches during daylight are generally less in near-shore coastal waters (Cowan \& Shaw 1988, Epifanio \& Garvine 2001).

The goal of this study was to determine whether patterns of larval ingress differ between wide coastal plain estuaries and narrow barrier island inlets, which are widely taken as the standard pattern. Specifically, we compared the relative abundance and distribution of Atlantic croaker larvae between the mouth of Chesapeake Bay, nearshore, and offshore stations of the adjacent coastal waters. In addition to patterns of abundance, we compared age, length, and growth rates of Atlantic croaker larvae collected outside the bay mouth to those collected at the bay mouth. In deference to the inlet model, we hypothesized that Atlantic croaker larvae would be more abundant on the north (flood dominated) portion of the bay mouth. In contrast to the inlet model, we hypothesized that croaker larvae would ingress at depth, because larvae competent to settle are concentrated in areas of net inflow. We also hypothesized that croaker larvae collected at the northern inshore stations would be more competent to settle (i.e. larger and older) than larvae collected offshore or in ebb-dominated locations.

\section{MATERIALS AND METHODS}

Study site. Chesapeake Bay, USA, is the world's second largest estuary and is typical of wide, partially mixed, coastal plain estuaries (Valle-Levinson et al. $1998,2001)$. The bay is $\sim 300 \mathrm{~km}$ long with a relatively deep and narrow central channel confined by a sill at its mouth. The bay mouth consists of 2 channels separated by shoals; the North Channel is approximately $13 \mathrm{~m}$ deep, and the Chesapeake Channel is approximately $10 \mathrm{~m}$ deep. Both channels are characterized by classic gravitational circulation modified by wind and water discharge (Valle-Levinson et al. 1998, 2001). Northeasterly winds prevail from late summer to early spring, causing net barotropic inflow and an increase in subtidal sea surface elevation at the bay mouth (Paraso \& Valle-Levinson 1996). The interaction among the 3 semidiurnal tidal constituents $\left(\mathrm{M}_{2}, \mathrm{~N}_{2}\right.$, and $\left.\mathrm{S}_{2}\right)$ generates fortnightly and monthly variability in the tidal currents (Valle-Levinson et al. 1998, 2001). During this study, spring tide conditions dominated. Further, freshwater outflow from the James River was lower than normal (USGS gauging station 02037500), and wind velocities averaged $10.4 \mathrm{~km} \mathrm{~h}^{-1}$ with a strong westerly (offshore) component.

Ichthyoplankton sampling. Larval fish were collected at 38 stations (Fig. 1) in the coastal ocean adjacent 

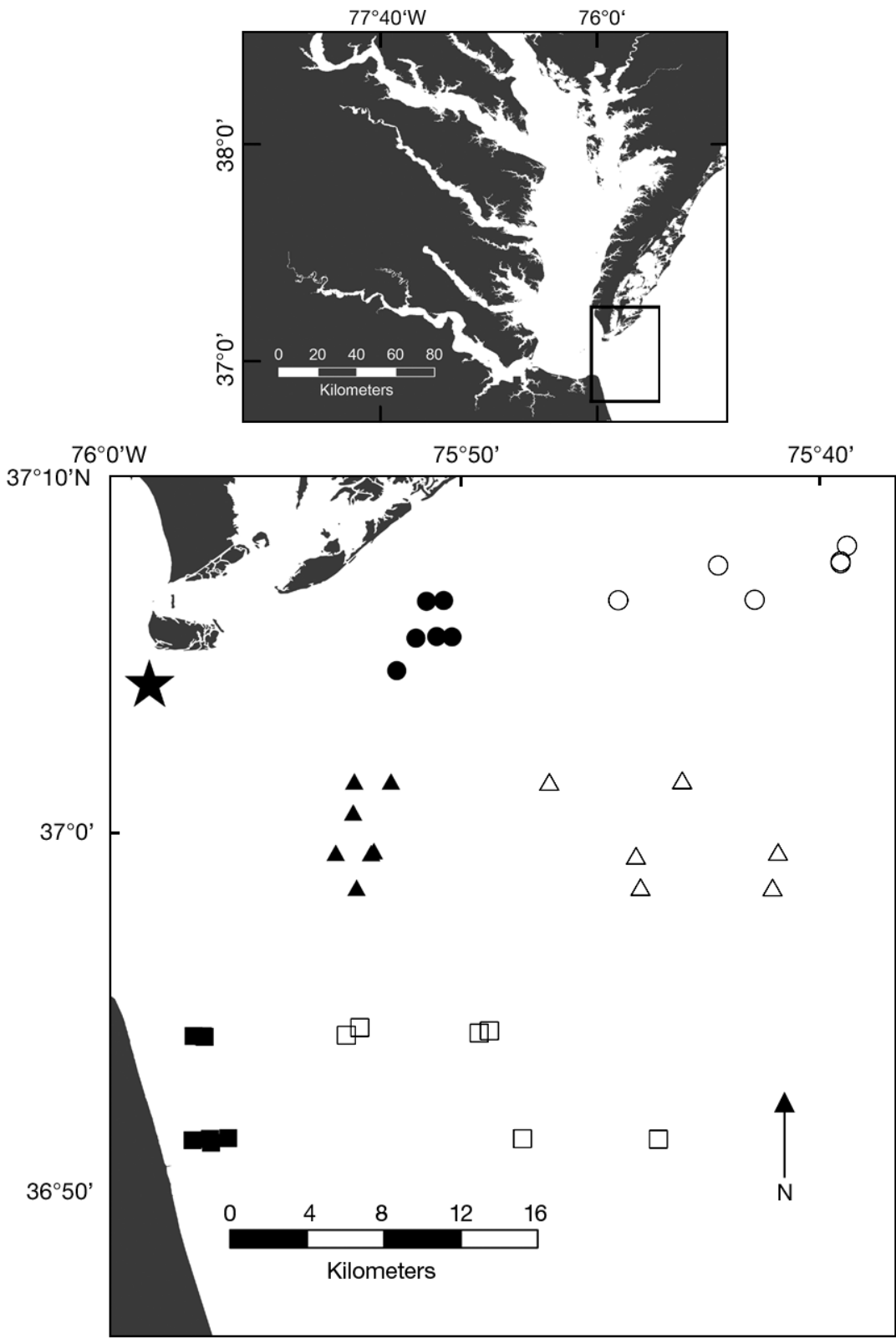

Fig. 1. Sampling locations at the mouth of Chesapeake Bay and adjacent coastal ocean. Symbols are grouped according to zone and are as follows:

-, north nearshore $(\mathrm{N}-\mathrm{N})$; O, north offshore $(\mathrm{N}-\mathrm{O}) ;$ $\Delta$, middle offshore $(\mathrm{M}-\mathrm{O}) ; \mathbf{\square}$, south nearshore $(\mathrm{S}-\mathrm{N}) ; \quad \square$, south offshore (S-O); $\star$, bay mouth (BM)

to Chesapeake Bay between 00:23 h on 14 November and $12: 12 \mathrm{~h}$ on 16 November 2000 from the RV 'Cape Hatteras' to examine mesoscale variability in croaker larval abundance. Stations were grouped from north to south (north, $N_{i}$ mid, $M$; south, S) and nearshore (N) or offshore (O) into 6 zones (e.g. north nearshore: N-N; south offshore: S-O; see Fig. 1). Larval fish were collected with a $1 \mathrm{~m}^{2}$ Tucker trawl that was actively towed and equipped with 3 nets. Each net had a GO Model 2030 (General Oceanics) flowmeter strung across the mouth. The first net of the tucker trawl (333 $\mu \mathrm{m}$ mesh size) from the sea surface to the bottom. At the bottom, the first net was closed and the second net was opened. The second net $(950 \mu \mathrm{m}$ mesh size) fished from the bottom to half the distance to the surface where it was closed (deep net). The third net (also $950 \mu \mathrm{m}$ mesh size) was opened and fished to the surface (shallow net). The mean \pm SE sample duration was $160.7 \pm$ $6.7 \mathrm{~s}$, resulting in a mean sample volume of $209.7 \pm 10.6 \mathrm{~m}^{3}$. All samples were preserved in $95 \%$ ethanol.

Additional larval fish were collected at a fixed station in the mouth of Chesapeake Bay (Fig. 1). At the bay mouth station, sampling was conducted from the NOAA ship 'Ferrel' between 22:00 h on 13 November and 10:00 h on 17 November 2000. In total, 83 samples were collected. Each collection consisted of 4 channel nets attached to a cable deployed from the stern of the ship. The ship was at anchor, and the cable was attached to another anchor so that the nets were able to orient into the current and fish passively. Nets were $1 \mathrm{~m}^{2}$, with $950 \mu \mathrm{m}$ mesh, and located at 1, 4, 8, and $12 \mathrm{~m}$ deep. Each net had a GO Model 2030 (General Oceanics) flowmeter strung across the mouth. Nets fished for approximately $1 \mathrm{~h}$, resulting in a mean \pm SE sample volume of $791.4 \pm 20.7 \mathrm{~m}^{3}$. Nets were emptied and immediately redeployed for another $1 \mathrm{~h}$.

Hydrographic sampling. Concurrent with each net collection, the temperature and salinity of the water column was measured using an SBE-19 (Seabird) CTD probe. Temperature and salinity were binned into $1 \mathrm{~m}$ depth intervals. The average of each $1 \mathrm{~m}$ interval was calculated to determine whether the water column was mixed or stratified by temperature and salinity. Because little stratification was present (temperature varied by $<0.1^{\circ} \mathrm{C}$ and salinity varied by $<1.0$ from surface to bottom), we calculated a simple average of water column temperature and salinity. A temperature-salinity (T-S) plot was used to determine whether our larval fish samples were collected in multiple water masses or whether they were derived from a single water mass.

Laboratory processing. In the laboratory, larval fishes were sorted and identified to the lowest taxo- 
nomic level possible. We enumerated all croaker larvae and randomly sub-sampled 10 individuals from each net collection or all individuals if fewer than 10 were collected in a net. We measured standard length $(\mathrm{SL}, \mathrm{mm})$ and extracted the sagittal otoliths on all subsampled croaker. Otoliths were embedded in thermal plastic cement and ground to the core, and the daily rings were counted at $1000 \times$ magnification under a light microscope. All otoliths were read without prior knowledge of fish size or collection location. Ages were estimated by adding $5 \mathrm{~d}$ to the number of daily increments in the otoliths to account for delay in deposition of the first daily increment (Nixon \& Jones 1997).

Abundance analyses. We examined abundance of croaker larvae collected in the coastal ocean to assess spatial patterns occurring among ingressing larvae. We used analysis of variance (ANOVA) with net depth (net 2 or 3, i.e. bottom or top half of the water column), date, daylight (day or night), and zone as independent variables (along with all first order interactions) and the number of croaker larvae $100 \mathrm{~m}^{-3}$ as the response variable. For this analysis, we did not use data collected from the first net because it was not fished at every sample site, but used abundance information from nets 2 and 3, which were fished at all stations and provided deep and shallow depth-specific abundances. All abundance data were natural log transformed to meet normality (Shapiro-Wilk $W=0.9813$, $\mathrm{p}=0.5193$ ) and equality of variance (Folded $F^{\prime}=1.08$, $\mathrm{p}=0.8325$ ) assumptions, and a significance level of $\alpha=$ 0.05 was used for all comparisons. When the main effects in any of the abundance analyses were significant, we used Tukey's multiple comparison procedure to identify differences.

To determine whether time of collection, daylight (day or night), date, or net depth had a measurable effect on the abundance of croaker larvae collected in the bay mouth, we used a mixed model repeated measures ANOVA design. Collection time was a repeated measures effect while net depth, date, and daylight were fixed effects. We tested these data for sphericity using Mauchly's sphericity test, which examines the form of the common covariance matrix. A spherical matrix has equal variances and covariances equal to 0 . The common covariance matrix of the transformed within-subject variables must be spherical, or the $F$-tests and associated p-values for the univariate approach to testing within-subjects hypotheses are invalid. Because we failed to reject the null hypothesis (Mauchly's criterion $=0.0368, \chi^{2}=8.99, p=0.1096$ ), we proceeded to test our data while assuming a compound symmetry type variance structure around the repeated measure (Littell et al. 2006).

In addition to individual analyses for fixed site and coastal ocean collections, we combined these 2 data sets to test the null hypothesis that larval pooling is occurring before ingress into Chesapeake Bay. The stations sampled in the coastal ocean were divided into 2 areas (offshore and nearshore). We examined the effects of location (i.e. bay mouth, nearshore, offshore), day, daylight, and depth (shallow versus deep) on croaker larval abundance using a repeated measures mixed model. We assumed compound symmetry variance structure around the repeated measure. Several issues were considered before this test was carried out. First, there were obvious differences in collection methods between the bay mouth site (passive channel nets) and coastal collections (active stepped oblique tows). We were confident in pooling these 2 data sets because other researchers have shown the validity of pooling samples from active and passive gears (Joyeux 1998, Forward et al. 1999) and because currents in the Chesapeake Bay mouth are often very strong, thus minimizing the possibility of net avoidance by larval croaker. Joyeux (1998) examined this as part of a larger project and found that active and passive gears were equally efficient and furnished compatible estimates of abundance in inlets. Further, if biases were occurring in our data, SL in passive samples would be skewed towards smaller larvae than in active samples. This was not the case and will be addressed further in the Discussion. Additionally, the depth bins at which samples were collected from coastal stations did not match those at the bay mouth where samples were depth discrete. To overcome this limitation, we pooled the 1 and $4 \mathrm{~m}$ channel nets into a shallow depth bin and the 8 and $12 \mathrm{~m}$ channel nets into a deep depth bin similar to the depth bins we observed in the coastal collections. We felt justified in pooling channel nets into these depth bins because there were no statistical differences within these pooled categories (see [Results]), while there were statistical differences across these categories.

Length and age distribution analyses. We used empirical quantile-quantile $(\mathrm{QQ})$ plots to identify differences in the SL and age distributions of croaker larvae among locations (Wilk \& Gnanadesikan 1968, Chambers et al. 1983). This method allows comparisons between 2 distributions by describing their shapes using quantiles. The QQ plot is constructed by plotting the quantiles of 1 empirical distribution against the quantiles of a corresponding distribution. Differences in the cumulative distribution function can be assessed graphically through the QQ plot or statistically by comparing the slope of the regression to 1 and the intercept to 0 (Post \& Evans 1989). A slope other than 1 indicates that the 2 distributions differ by a multiplicative constant, and an intercept other than 0 indicates that the 2 distributions differ by an additive constant. 
Further, depth may have an impact on the observed length and age distributions. We used ANOVA to determine the effect of location (i.e. bay mouth, nearshore, or offshore) and depth on length and age because of the multiple factors involved, and we restricted these analyses to the combined data set that included collections from various gears.

Growth rate analyses. We used the Laird form of the Gompertz growth model (Laird et al. 1965) to describe the growth of croaker larvae. The model we used was $\mathrm{SL}=\mathrm{SL}_{0} / \exp \left\{\left(\mathrm{A}_{0} / \alpha\right) \times[1-\exp (-\alpha \times \mathrm{Age})]\right\}$, where $\mathrm{SL}_{0}$ is the estimated SL at hatching, $\mathrm{A}_{0}$ is the specific growth rate at hatching, and $\alpha$ is the rate of exponential decay of the specific growth rate. To determine whether there were differences in the growth of larvae collected in different areas we used a likelihood ratio test (Kimura 1980).

\section{RESULTS}

\section{Hydrographic variability}

$\mathrm{T}$ and $\mathrm{S}$ profiles revealed a vertically mixed water column at all sample stations. Because water column profiles were homogenous, we averaged $\mathrm{T}$ and $\mathrm{S}$ from each profile into single values for each station and constructed a T-S plot to examine relationships among stations (Fig. 2). All stations sampled on Day 1 clustered together in the T-S diagram. On Day 1, water temperatures were 13 to $14^{\circ} \mathrm{C}$ and salinity was 29 to 32 . On Days 2 and 3, temperatures were much cooler (10 to $12^{\circ} \mathrm{C}$ ) than on Day 1 , but salinities were similar with the exception of the south nearshore stations. At the south nearshore stations, salinities were consistently lower than at other stations on all days, particularly Days 2 and 3, when salinities were 27 to 28 .

\section{Croaker variability}

We captured 882 croaker larvae at the 36 coastal ichthyoplankton sample sites. Net depth, date, daylight, and zone combined to explain a significant portion of the variation in croaker larval abundance among locations $\left(F_{48,71}=3.28, \mathrm{p}=0.0003\right)$. Among main effects, only net depth $\left(F_{1,71}=21.08, \mathrm{p}<0.0001\right)$ had a significant impact on the abundance of croaker larvae (Fig. 3). The mean \pm SE abundance in the deep nets was $8.5 \pm$ 1.5 larvae $100 \mathrm{~m}^{-3}$, while the mean abundance in the shallow nets was $3.4 \pm 1.3$ larvae $100 \mathrm{~m}^{-3}$. Neither day $\left(F_{2,71}=1.44, \mathrm{p}=0.2464\right)$ nor daylight $\left(F_{1,71}=0.01, \mathrm{p}=\right.$ $0.9193)$ nor zone $\left(F_{5,71}=1.89, \mathrm{p}=0.1133\right)$ had a significant effect on croaker larval abundance. However, there was a significant net depth $\times$ zone interaction

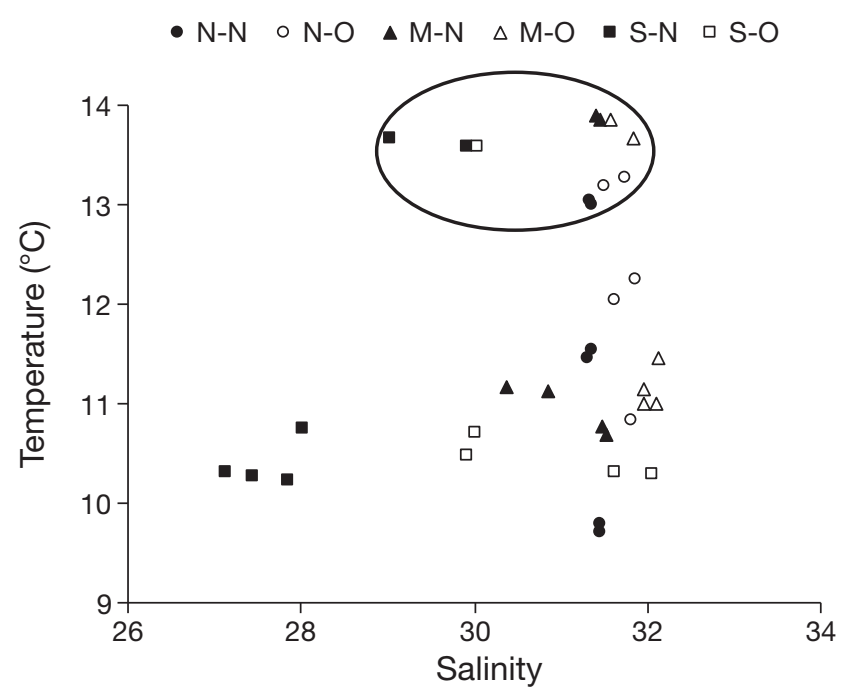

Fig. 2. Temperature-salinity plot of mean water column data for each sample station just outside the mouth of Chesapeake Bay. Station abbreviations: see Fig. 1. All water mass variables for Day 1 are in the ellipse

$\left(F_{5,71}=3.25, \mathrm{p}=0.0132\right)$. To explain this interaction, we examined the simple effects. Among nearshore coastal stations (N-N, M-N, S-N), the abundance of croaker larvae was significantly greater in deep nets than in shallow nets in the N-N and M-N zones ( $\mathrm{p}=0.0002$ and $\mathrm{p}=$ 0.0017 , respectively) but not different within the S-N zone $(p=0.7016)$. There were no differences in croaker larval abundances in deep or shallow nets from zones farther offshore (N-O, M-O, S-O; all p > 0.5926). Additionally, there were no differences in croaker larval abundances from any station's deep (or shallow) net when compared with the same depth net at another station within the same north or south zone (e.g. N-N deep versus $\mathrm{N}-\mathrm{O}$ deep or $\mathrm{S}-\mathrm{N}$ shallow versus $\mathrm{S}-\mathrm{O}$ shallow; all comparisons $\mathrm{p}>0.3672$ ).

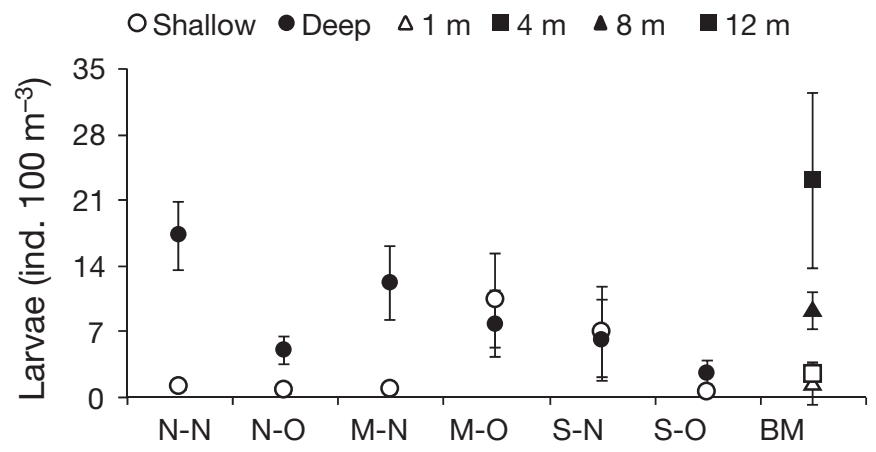

Fig. 3. Micropogonias undulatus. Mean \pm SE abundance of Atlantic croaker larvae from coastal stations in the top half (shallow, open circles) and bottom half (deep, filled circles) of the water column as well as mean abundance from the bay mouth (BM) station. Net sets at the BM station were depth discrete $(1,4,8$, and $12 \mathrm{~m})$ 
We captured 7356 croaker larvae in 76 ichthyoplankton samples from the bay mouth station. At this station, depth (Fig. 3; $F_{3,154}=6.47, \mathrm{p}=0.0002$ ), time (Fig. 4; $\left.F_{1,154}=6.49, \mathrm{p}=0.0118\right)$, and daylight $\left(F_{1,154}=11.64\right.$, $\mathrm{p}=0.0008)$ affected croaker larval abundance, while there was no influence of date $\left(F_{3,154}=2.09, \mathrm{p}=0.1037\right)$ nor any interaction between terms. Further, croaker larval abundance at $12 \mathrm{~m}$ was greater than abundance at $1 \mathrm{~m}(\mathrm{p}<0.0001)$ or $4 \mathrm{~m}(\mathrm{p}<0.0001)$, but not different than abundance at $8 \mathrm{~m}(\mathrm{p}=0.1846)$. Croaker larval abundance at $8 \mathrm{~m}$ was greater than abundances at $1 \mathrm{~m}$ ( $p=0.0018)$ or $4 \mathrm{~m}(\mathrm{p}<0.0001)$, while abundance at $1 \mathrm{~m}$ and $4 \mathrm{~m}$ were not different $(\mathrm{p}=0.9982)$. Because there were no differences in croaker larval abundance at 1 and $4 \mathrm{~m}$ or at 8 and $12 \mathrm{~m}$, respectively, we pooled these categories into shallow and deep depth bins to facilitate comparisons with the coastal stations.

Comparisons of bay mouth and coastal stations revealed a strong effect of depth (Fig. $5_{;} F_{1,6}=34.76$, $\mathrm{p}=0.0011)$ and daylight $\left(F_{1,8}=29.77, \mathrm{p}=0.0006\right)$ on abundance, but no effect of location $\left(F_{2,4}=0.42, \mathrm{p}=\right.$ $0.6848)$ or day $\left(F_{2,4}=2.45, \mathrm{p}=0.2017\right)$. No first order interactions were significant. This indicates that the supply of croaker larvae was continuous across the locations we examined and that larvae are not pooling at the bay mouth station relative to the coastal stations. However, as with both previous analyses, depth had a large influence on croaker larval abundance, where mean $\pm \mathrm{SE}$ abundance was $15.1 \pm 4.1$ larvae $100 \mathrm{~m}^{-3}$ in deep nets and $2.8 \pm 0.8$ larvae $100 \mathrm{~m}^{-3}$ in shallow nets.

\section{Length and age comparisons}

Croaker larval length and age varied substantially based on capture location (Table 1). The length distribution of croaker larvae captured at the north off-

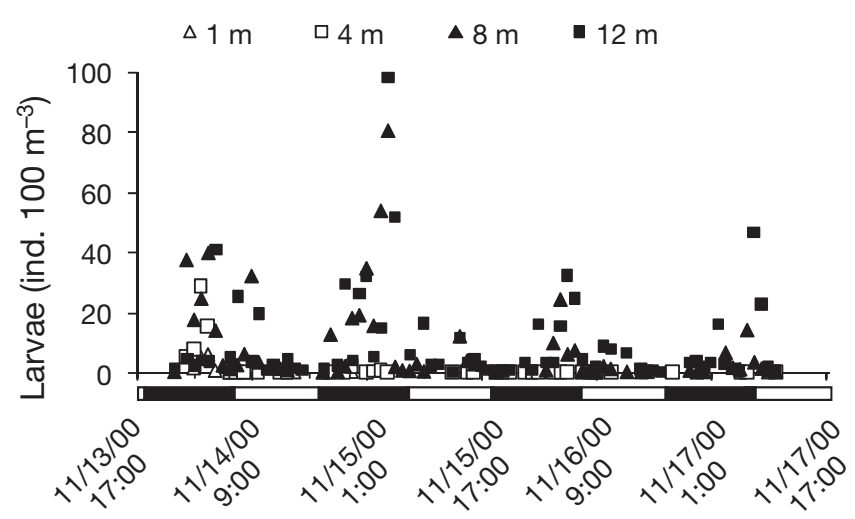

Fig. 4. Micropogonias undulatus. Larval density at the BM station. Collections were made hourly beginning at 22:00 $\mathrm{h}$ on 13 November 2000 and ending at 10:00 h on 17 November 2000. The alternating light and dark bars represent an approximate 10:14 h light:dark cycle shore stations was shifted towards larger individuals relative to the middle and south offshore stations, but there were no differences for middle or south offshore stations (Table 2). There were no differences in the age distributions of croaker larvae in any of the offshore (N-O, M-O, S-O) stations. Among nearshore stations, there were significant differences in the length and age distributions of croaker larvae. At the northern nearshore stations, there were larger and older larvae than at both the middle and southern nearshore stations. Additionally, there were larger larvae at southern stations than at middle stations, but the same was not true for age. Comparisons of length and age distributions between near-shore and offshore stations generally resulted in larger and older larvae at nearshore stations than corresponding offshore stations.

In addition to length and age comparisons among nearshore and offshore coastal stations, we also compared the overall length and age distributions from the combined nearshore and offshore coastal stations with the bay mouth station. The length distributions were

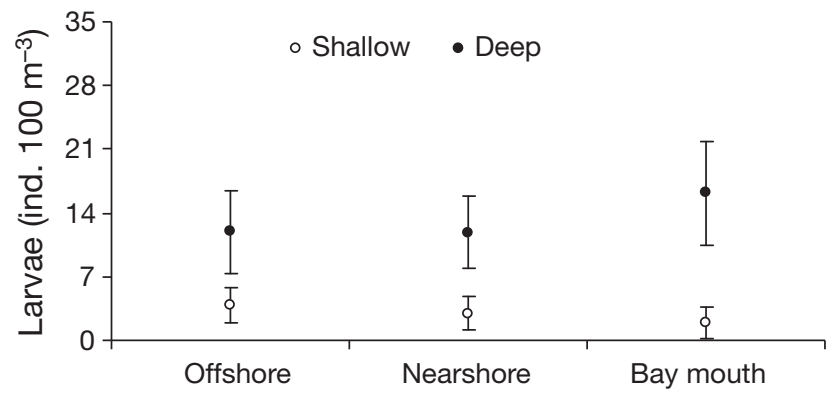

Fig. 5. Micropogonias undulatus. Average larval abundance in deep and shallow nets from the offshore and nearshore coastal stations and the pooled deep and shallow nets from the bay mouth station

Table 1. Micropogonias undulatus. Mean lengths and ages of Atlantic croaker larvae from coastal stations adjacent to Chesapeake Bay and pooled offshore, nearshore, and bay mouth stations. The notation $\mathrm{X}-\mathrm{X}$ indicates the north-south location (N, M [mid], S) followed by the position nearshore (N) or offshore $(\mathrm{O})$

\begin{tabular}{|lcc|}
\hline Location & Length $(\mathrm{mm})$ & Age $(\mathrm{d})$ \\
\hline $\mathrm{N}-\mathrm{N}$ & 12.3 & 65.8 \\
M-N & 8.6 & 51.5 \\
S-N & 9.7 & 52.1 \\
N-O & 7.6 & 47.3 \\
M-O & 7.5 & 45.7 \\
S-O & 7.7 & 44.7 \\
Offshore & & \\
Nearshore & 7.6 & 45.8 \\
Bay mouth & 10.6 & 58.2 \\
\end{tabular}


shifted towards larger and older croaker larvae at the bay mouth station compared with coastal stations (Table 3). As a result, the average length and age both followed an increasing trend as larvae were transported inshore (Table 1).

Because of significant length and age differences among bay mouth and coastal ocean stations (i.e. nearshore and offshore), we examined depth related hypotheses with station as an explanatory variable. For length, station was significant $\left(F_{2,1349}=218.74, \mathrm{p}<\right.$ 0.0001) showing the same pattern as with $Q Q$ plots, but there was no effect of depth $\left(F_{1,1349}=1.63, \mathrm{p}=\right.$ $0.2020)$. For age, station was significant $\left(F_{2,1349}=\right.$ 239.06, p < 0.0001), and there was an effect of depth $\left(F_{1,1349}=4.67, \mathrm{p}=0.0308\right)$. This indicates that there are older but not necessarily larger croaker larvae in deeper waters.

Table 2. Micropogonias undulatus. Slopes, intercepts, and associated p-values from quantile-quantile comparisons of Atlantic croaker larval age and length among coastal stations. $p$-values in bold indicate that the slope is significantly different from 1 or that the intercept is significantly different from 0 , and are based on a Bonferroni corrected $\alpha=0.0056$. See Fig. 1 for station abbreviations

\begin{tabular}{|lcccrc|}
\hline \multirow{2}{*}{ Comparison } & Variable & Slope & $\mathrm{p}$ & Intercept & $\mathrm{p}$ \\
\hline N-O vs. M-O & Length & 0.80 & $<0.7407$ & 1.38 & $<\mathbf{0 . 0 0 0 1}$ \\
& Age & 0.95 & $<0.2294$ & 0.74 & $<0.8049$ \\
N-O vs. S-O & Length & 0.65 & $<0.7890$ & 2.76 & $<\mathbf{0 . 0 0 0 1}$ \\
& Age & 0.87 & $<0.0377$ & 3.55 & $<0.0469$ \\
M-O vs. S-O & Length & 0.79 & $<0.4848$ & 1.81 & $<\mathbf{0 . 0 0 0 3}$ \\
& Age & 0.87 & $<0.4041$ & 4.91 & $<\mathbf{0 . 0 0 2 2}$ \\
N-N vs. M-N & Length & 1.23 & $<\mathbf{0 . 0 0 0 1}$ & -6.46 & $<\mathbf{0 . 0 0 0 1}$ \\
& Age & 1.11 & $\mathbf{< 0 . 0 0 0 9}$ & -11.77 & $<0.0789$ \\
N-N vs. S-N & Length & 0.67 & $<\mathbf{0 . 0 0 0 1}$ & 1.41 & $<0.2093$ \\
& Age & 0.93 & $<\mathbf{0 . 0 0 0 5}$ & -1.86 & $<0.8627$ \\
M-N vs. S-N & Length & 0.49 & $<0.0135$ & 5.51 & $<\mathbf{0 . 0 0 0 1}$ \\
& Age & 0.99 & $<0.7845$ & -0.12 & $<0.9766$ \\
N-N vs. N-O & Length & 0.96 & $<0.6100$ & -4.14 & $<\mathbf{0 . 0 0 0 2}$ \\
& Age & 0.89 & $<0.0411$ & -3.33 & $<0.3191$ \\
M-N vs. M-O & Length & 0.60 & $<\mathbf{0 . 0 0 0 1}$ & 2.37 & $<\mathbf{0 . 0 0 0 1}$ \\
& Age & 0.83 & $\mathbf{< 0 . 0 0 0 1}$ & 7.80 & $<\mathbf{0 . 0 0 0 1}$ \\
S-N vs. S-O & Length & 0.78 & $<0.0109$ & 0.12 & $<0.8792$ \\
& Age & 0.56 & $\mathbf{< 0 . 0 0 0 1}$ & 15.96 & $<\mathbf{0 . 0 0 0 1}$ \\
& & & &
\end{tabular}

Table 3. Micropogonias undulatus. Slopes, intercepts, and associated p-values from quantile-quantile comparisons of Atlantic croaker larval length and age between pooled coastal stations (near-shore, $\mathrm{N}$, and offshore, $\mathrm{O}$ ) and the bay mouth station (BM). p-values in bold indicate that the slope is significantly different from 1 or that the intercept is significantly different from 0 based on a Bonferroni corrected $\alpha=0.0167$

\begin{tabular}{|c|c|c|c|c|c|}
\hline Comparison & Variable & Slope & $\mathrm{p}$ & Intercept & $\mathrm{p}$ \\
\hline \multirow[t]{2}{*}{ BM vs. $\mathrm{N}$} & Length & 0.74 & $<0.0001$ & 2.84 & $<0.0001$ \\
\hline & Age & 0.63 & $<0.0001$ & 22.52 & $<0.0001$ \\
\hline \multirow[t]{2}{*}{ BM vs. O } & Length & 1.25 & $<0.0001$ & 1.37 & $<0.0002$ \\
\hline & Age & 1.36 & $<0.0001$ & -2.57 & $<0.0459$ \\
\hline \multirow[t]{2}{*}{$\mathrm{N}$ vs. $\mathrm{O}$} & Length & 1.60 & $<0.0001$ & -1.44 & $<0.0040$ \\
\hline & Age & 2.11 & $<0.0001$ & -37.66 & $<0.0001$ \\
\hline
\end{tabular}

\section{Growth rate comparisons}

We determined the age of 258 croaker larvae from coastal stations and 1095 from the bay mouth to estimate to fit the larval length and age data for nearshore and off shore coastal stations separately. However, we found that there were no differences in these 2 growth curves (Fig. 6a; likelihood ratio $=4.68, p=0.1965$ ). Therefore, combined the data to form a single coastal group, and growth model and the coastal growth model (Fig. 6b; likelihood ratio $=0.70, \mathrm{p}=0.8738$ ). Therefore, we combined all croaker larvae together to develop a single growth model, where $\mathrm{SL}_{0}=0.121, \alpha=0.045$, and $\mathrm{A}_{\mathrm{t}}=4.828$.

\section{DISCUSSION}

Although it is generally recognized that larval fish pool at nearshore fronts or in estuary mouths before recruitment, our data indicate that this may not be a consistent feature of ingress into Chesapeake Bay. We found no differences in densities of croaker larvae between the bay mouth station and the nearshore stations that were located about $7 \mathrm{~km}$ seaward. This indicates that transport across this distance was a continuous process unlike that observed for barrier island inlets (Boehlert \& Mundy 1988, Hettler \& Hare 1998). The most distant offshore stations we examined were up to $30 \mathrm{~km}$ beyond the bay mouth station. Similarly, we found no evidence that larvae are pooling in this region. This is particularly intriguing because larvae have to cross the Chesapeake Bay plume, and we expected a slowing of transport inshore and subsequent pooling at this front. However, as Reiss \& McConaugha (1998) pointed out, rapid cross frontal transport can occur with upwelling conditions in this system, which could explain the transport pattern we observed. Moreover, Cowan \& Shaw (1988) found a similar density pattern for Atlantic croaker larvae collected in the continental shelf 


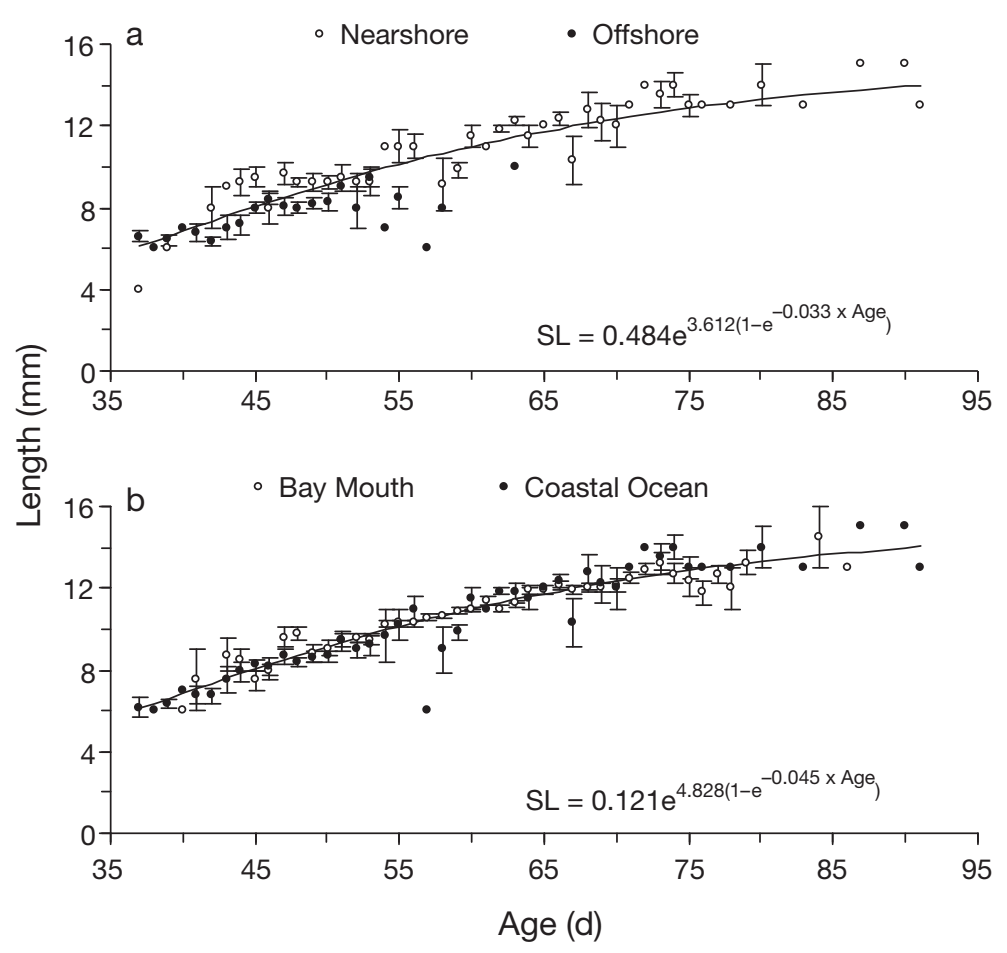

Fig. 6. Micropogonias undulatus. Laird-Gompertz growth model describing growth of larval Atlantic croaker from (a) the nearshore and offshore coastal ocean and (b) the pooled coastal zones and the bay mouth station

ward et al. 1999). However, this pattern has not always held in all bays and inlets (Holt et al. 1989, Raynie \& Shaw 1994, Joyeux 1998), indicating that other factors such as inlet morphology or wind forcing may play important roles in determining patterns of larval ingress. Moreover, most of these data have been collected at barrier island inlets, which have a much more constrained flow than that of Chesapeake Bay. For example, in Chesapeake Bay, a net influx of water occurs at depth (ValleLevinson et al. 1998, 2001) in addition to Coriolis-mediated influxes. Therefore, it is possible that croaker larvae can ingress into Chesapeake Bay at depth regardless of position across the bay mouth.

Depth is an important component regulating abundance of croaker larvae captured in a variety of locations in and outside the mouth of Chesapeake Bay. Croaker larval captured in mesoscale collections outside the mouth of the bay were significantly more abundant in the bottom half of the water column. Likewise, croaker larval abundance at the bay mouth station showed a significant trend with depth, where average abundance from the

waters off Louisiana, USA, that indicated an uninterrupted pattern of cross shelf transport and ingress into coastal bays. These collections extended across the Mississippi River plume, which is essentially an estuary without an inlet or mouth. Due to the size of the Chesapeake Bay mouth, ingress may not be controlled by the same mechanisms that operate at barrier island inlets that result in nearshore accumulation. The processes that act to regulate larval ingress into Chesapeake Bay may be more similar to those processes acting to transport larvae to nearshore regions in the Gulf of Mexico.

We found that our a priori prediction of increased density of croaker larvae at the northern stations in Chesapeake Bay was not supported. There were no differences in croaker larval abundances from north to south across nearshore and offshore stations in coastal waters adjacent to the bay mouth. It is not surprising that there were no differences in croaker larval density at offshore stations because adult croaker are believed to spawn over large portions of the mid- to outer continental shelf (Norcross 1991). In contrast, croaker larvae captured at northern nearshore stations were located in an area that shows a net influx of water at all depths. According to the inlet model, this area should harbor greater larval densities (Boehlert \& Mundy 1988, Hettler \& Hare 1998, Churchill et al. 1999a, For- deeper (8 and $12 \mathrm{~m}$ ) channel nets was much greater than average abundance from the shallower (1 and $4 \mathrm{~m}$ ) channel nets. This provides additional support for studies that have found that croaker larval ingress is accomplished through residual bottom inflow (Norcross 1991, Hare et al. 2005). Further, we found limited evidence that croaker larvae at depth were older than those shallower in the water column, indicating that ontogeny plays a role during ingress (Hare et al. 2005, 2006). For example, sensory faculties and swimming capabilities change dramatically during larval development and affect the vertical distribution of larvae in the water column, resulting in more effective regulation of vertical position in the water column, which will ultimately allow the larvae to use additional transport mechanisms to find suitable nursery habitat.

We found conflicting evidence for the role of daylight on ingress. For the bay mouth samples, daylight played an important role and is also likely tied to flood tide conditions where croaker larvae were significantly more abundant at night and showed a strong cyclical pattern. However, at the coastal ocean stations, daylight seemingly did not have any control over ingress. This may have been because most samples collected during daylight hours were collected just after sunrise, thus not allowing sufficient time for croaker larvae to show a response to light. Overall, 
daylight had a similar impact on croaker larval abundance as depth. This general pattern has often been noted in other studies and has been attributed to several processes including net avoidance, migration away from sampled areas, or diurnal vertical migration (Raynie \& Shaw 1994, Joyeux 1998, Forward \& Tankersley 2001).

The average length of croaker larvae offshore was approximately $7.5 \mathrm{~mm}$ SL, whereas larvae nearshore and in the bay mouth were approximately $10 \mathrm{~mm} \mathrm{SL}$, with the exception of the middle inshore station, where average length was just over $8 \mathrm{~mm}$ SL. Croaker larvae begin to ingress into bays and estuaries at a mean SL of approximately 8 to $11 \mathrm{~mm}$ in North Carolina inlets (Warlen \& Burke 1990, Hettler 1998). Croaker larval settlement occurs in Texas estuaries at a size of 10 to $14 \mathrm{~mm}$ SL (Rooker et al. 1998); therefore, most croaker larvae caught in the bay mouth and nearshore stations were competent to settle. This result for croaker is generally in agreement with the 'competent size hypothesis,' which showed that the age at settlement in black rockfish Sebastes inermis was variable but highly dependent on size (Pasten et al. 2003). Similarly, croaker larval ages vary much more than length in the deeper zones as they seek nursery habitat.

We observed a strong trend of increasing length and age of croaker larvae from the offshore stations to the nearshore stations and into the bay mouth station. This is an expected pattern when larval pooling does not occur at any nearshore locations or within an estuary mouth. This has been shown for croaker and other offshore-spawning species that ingress into bays and estuaries along the US east coast (Lewis \& Judy 1983, Flores-Coto \& Warlen 1992, Hettler \& Hare 1998). However, other patterns have emerged where mean length generally increases as larvae are advected towards land. For example Hettler \& Hare (1998), observed no difference in lengths of fish larvae onshore versus offshore on some sampling dates, while on most sampling dates patterns in length followed an expected distribution (Hettler \& Hare 1998). This pattern could be explained by larval pooling at nearshore fronts. However, if age and length are increasing from an offshore to onshore direction and there is no evidence of larval pooling at any stations, it would be interesting to compare transport rates of croaker larvae calculated from changes in the age structure and location (Warlen 1992, Schultz et al. 2005) to transport rates from larval transport models (Hare et al. 1999, Werner et al. 1999).

In addition to the strong onshore-offshore gradient in croaker larval length and age, we also observed a slightly skewed distribution of lengths and ages towards larger and older individuals in the northern nearshore stations relative to other nearshore stations.
There is limited evidence to suggest that larvae on the flood-dominated side of an inlet may be larger and older than on the ebb-dominated side of an inlet (Lyczkowski-Shultz et al. 1990, Forward et al. 1999). However, few studies have found evidence for this phenomenon (Holt et al. 1989, Hettler \& Hare 1998). Numerous physical differences exist between the types of inlets sampled in the studies that failed to detect differences in the age or length structure of larvae and those that did find differences. Therefore we cannot speculate as to what forces may cause this pattern in large part because of the physical differences between the Chesapeake Bay mouth and other studies where these differences have been shown.

Estimated ages (37 to $91 \mathrm{~d}$ ) of croaker larvae examined in this study are very similar to previous estimates for fish in the size range we examined (Warlen 1981, Cowan 1988). Mean growth rates outside Chesapeake Bay and at the bay mouth station are similar to croaker larvae captured in Chesapeake Bay (Nixon \& Jones 1997). Additionally, because we found no differences in the growth rates of croaker larvae captured in any of the locations we sampled, our results provide evidence that croaker larval ingress into Chesapeake Bay likely originated from a similar source region or experienced the same growth environments during transport. For example, ingress into Chesapeake Bay may be controlled by a very specific set of physical forcing effects such that only larvae placed in the 'right' parcel of water or water parcels that are generated from a specific place and time are able to make it to the Bay. However, to fully test these hypotheses, we will need many more observational data points (of which this study represents one) to build more sophisticated predictive models of ingress.

Although this study was not explicitly designed to elucidate mechanisms responsible for ingress of larval croaker into Chesapeake Bay, we feel that these results have provided an important starting point for future investigations as well as insight into ideas that have not yet been fully addressed. One of the limitations of our data was temporal duration. We only collected larval croaker in November. Even with this sample, we have shown that ingress into Chesapeake Bay can occur by very different processes than ingress through barrier island inlets. Future work should be conducted on a schedule to better assess variations that may be due to variable tidal conditions as well as different wind forcing (Hare et al. 2005). Work should also be directed at determining what mechanisms lead to phenomena such as larval pooling and increased abundances at flood-dominated sites and what mechanisms lead to a breakdown of these phenomena. Although our use of oblique tows outside the mouth of Chesapeake Bay provided us with data on depth pref- 
erences, we believe the use of finer-scale depthspecific collections in these regions would greatly enhance our knowledge of and the ability to model the ingression process.

Elucidating the contributions of active and passive transport mechanisms to the ingression process remains a fundamental goal for understanding and predicting the population dynamics of estuarine dependent species. Modeling larval transport on the continental shelf is accomplished through sophisticated models (Hare et al. 1999, Werner et al. 1999), but these models have not been explicitly linked to ingress models that move larvae from shelf areas into bays and estuaries. Most studies have assumed that larvae arriving within a certain distance of the estuary mouth are able to ingress to nursery areas. Results of our study and that of Hare et al. (2005) indicate that there may be processes operating within estuary mouths that structure the ingress progress, thus potentially affecting recruitment dynamics to estuarine nursery habitats.

Acknowledgements. We thank J. Hare for participating in planning for and collecting the samples that went into this work. Additional thanks go to S. Turner for assistance in extraction and preparation of otoliths for age and growth analysis, D. N. Naik for statistical advice, and 4 anonymous reviewers whose comments improved the quality of this manuscript. Funding for this work was provided by a grant from the National Science Foundation (OCE-0525964 and OCE9876565) to C.M.J.

\section{LITERATURE CITED}

Boehlert GW, Mundy BC (1988) Roles of behavior and physical factors in larval and juvenile fish recruitment to estuarine nursery areas. Am Fish Soc Symp 3:51-67

> Bradbury IR, Snelgrove PVR, Pepin P (2003) Passive and active behavioural contributions to patchiness and spatial pattern during the early life history of marine fishes. Mar Ecol Prog Ser 257:233-245

Chambers JM, Cleveland WS, Kleiner B, Tukey PA (1983) Graphical methods for data analysis. Wadsworth International Group, Belmont, CA, and Duxbury Press, Boston, MA

Churchill JH, Blanton JO, Hench JL, Luettich RA Jr, Werner FE (1999a) Flood tide circulation near Beaufort Inlet, North Carolina: implications for larval recruitment. Estuaries 22:1057-1070

Churchill JH, Forward RB, Luettich RA, Hench JL, Hettler WF, Crowder LB, Blanton JO (1999b) Circulation and larval fish transport within a tidally dominated estuary. Fish Oceanogr 8:173-189

> Coleman FC, Figueira WF, Ueland JS, Crowder LB (2004) The impact of United States recreational fisheries on marine fish populations. Science 305:1958-1960

Cowan JH Jr (1988) Age and growth of Atlantic croaker, Micropogonias undulatus, larvae collected in the coastal waters of the northern Gulf of Mexico as determined by increments in saccular otoliths. Bull Mar Sci 42:349-357

Cowan JH Jr, Shaw RF (1988) The distribution, abundance, and transport of larval sciaenids collected during winter and early spring from the continental-shelf waters off west Louisiana. Fish Bull (Wash DC) 86:129-142
Diamond SL, Crowder LB, Cowell LG (1999) Catch and bycatch: the qualitative effects of fisheries on population vital rates of Atlantic croaker. Trans Am Fish Soc 128: 1085-1105

Epifanio CE, Garvine RW (2001) Larval transport on the Atlantic continental shelf of North America: a review. Estuar Coast Shelf Sci 52:51-77

Flores-Coto C, Warlen SM (1993) Spawning time, growth, and recruitment of larval spot, Leiostomus xanthurus, into a North Carolina estuary. Fish Bull (Wash DC) 91:8-22

Fortier L, Leggett WC (1983) Vertical migrations and transport of larval fish in a partially mixed estuary. Can J Fish Aquat Sci 40:1543-1555

Forward RB Jr, Tankersley RA (2001) Selective tidal-stream transport of marine animals. Oceanogr Mar Biol Annu Rev 39:305-353

Forward RB Jr, Tankersley RA, Reinsel KA (1998) Selective tidal-stream transport of spot (Leiostomus xanthurus) and pinfish (Lagodon rhomboids, Linnaeus) larvae: contribution of circatidal rhythms in activity. J Exp Mar Biol Ecol 226:19-32

> Forward RB Jr, Reinsel KA, Peters DS, Tankersley RA and others (1999) Transport of fish larvae through a tidal inlet. Fish Oceanogr 8:153-172

Grothues TM, Cowen RK, Pietrafesa LJ, Bignami F, Weatherly GL, Flagg CN (2002) Flux of larval fish around Cape Hatteras. Limnol Oceanogr 47:165-175

Hare JA, Govoni JJ (2005) Comparison of average larval fish vertical distributions among species exhibiting different transport pathways on the southeast United States continental shelf. Fish Bull (Wash DC) 103:728-736

> Hare JA, Quinlan JA, Werner FE, Blanton BO and others (1999) Larval transport during winter in the SABRE study area: results of a coupled vertical larval behavior-threedimensional circulation model. Fish Oceanogr 8:57-76

> Hare JA, Thorrold S, Walsh H, Reiss CS, Valle-Levinson A, Jones C (2005) Biophysical mechanisms of larval fish ingress into Chesapeake Bay. Mar Ecol Prog Ser 303: $295-310$

> Hare JA, Walsh HJ, Wuenschel MJ (2006) Sinking rates of late-stage fish larvae: implications for larval ingress into estuarine nursery habitats. J Exp Mar Biol Ecol 330: 493-504

Hettler WF Jr (1998) Abundance and size of dominant winterimmigrating fish larvae at two inlets into Pamlico Sound, North Carolina. Brimleyana 25:144-155

Hettler WF, Hare JA (1998) Abundance and size of larval fishes outside the entrance to Beaufort Inlet, North Carolina. Estuaries 21:476-499

Holt SA, Holt GJ, Arnold CR (1989) Tidal stream transport of larval fishes into non-stratified estuaries. Rapp P-V Reun Cons Int Explor Mer 191:100-104

Joyeux JC (1998) Spatial and temporal entry patterns of fish larvae into North Carolina estuaries: comparisons among one pelagic and two demersal species. Estuar Coast Shelf Sci 47:731-752

Joyeux JC (1999) The abundance of fish larvae in estuaries: within-tide variability at inlet and immigration. Estuaries 22:889-904

Kasai A, Hill A, Fujiwara T, Simpson T (2000) Effects of the earth's rotation on the circulation in regions of freshwater influence. J Geophys Res C Oceans 105:16961-16969

Kimura DK (1980) Likelihood methods for the von Bertalanffy growth curve. Fish Bull (Wash DC) 77:765-776

> Laird AK, Tyler SA, Barton AD (1965) Dynamics of normal growth. Growth 29:233-248

Laprise R, Dodson JJ (1989) Ontogeny and importance of tidal 
vertical migrations in the retention of larval smelt Osmerus mordax in a well-mixed estuary. Mar Ecol Prog Ser 55: 101-111

Lewis RM, Judy MH (1983) The occurrence of spot, Leiostomus xanthurus, and Atlantic croaker, Micropogonias undulatus, larvae in Onslow Bay and Newport River estuary, North Carolina. Fish Bull (Wash DC) 81:405-412

Littell RC, Milliken GA, Stroup WW, Wolfinger RD, Schabenberger O (2006) SAS for mixed models, 2nd edn. SAS Institute Inc., Cary, NC

Lyczkowski-Shultz J, Ruple DL, Richardson SL, Cowan JH Jr (1990) Distribution of fish larvae relative to time and tide in a Gulf of Mexico barrier island pass. Bull Mar Sci 46: 563-577

Miller JM, Reed JP, Pietrafesa LJ (1984) Patterns, mechanisms, and approaches to the study of migrations of estuarine-dependent fish larvae and juveniles. In: McCleave JD, Arnold GP, Dodson JJ, Neill WH (eds) Mechanisms of migration in fishes. Plenum Press, New York, NY, p 209-225

Nelson WR, Ingham MC, Schaaf WE (1977) Larval transport and year-class strength of Atlantic menhaden, Brevoortia tyrannus. Fish Bull (Wash DC) 75:23-41

Nixon SW, Jones CM (1997) Age and growth of larval and juvenile Atlantic croaker, Micropogonias undulatus, from the Middle Atlantic Bight and estuarine waters of Virginia. Fish Bull (Wash DC) 95:773-784

Norcross BL (1991) Estuarine recruitment mechanisms of larval Atlantic croakers. Trans Am Fish Soc 120:673-683

Paraso MC, Valle-Levinson A (1996) Meteorological influences on sea level and water temperature in the lower Chesapeake Bay: 1992. Estuaries 19:548-561

Pasten GP, Katayama S, Omori M (2003) Timing of parturition, planktonic duration, and settlement patterns of the black rockfish, Sebastes inermis. Environ Biol Fishes 68: 229-239

Pietrafesa LJ, Janowitz GS (1988) Physical oceanographic processes affecting larval transport around and through North Carolina inlets. Am Fish Soc Symp 3:34-50

Post JR, Evans DO (1989) Size-dependent overwinter mortality of young-of-the-year yellow perch (Perca flavescens): laboratory, in situ enclosure, and field experiments. Can J Fish Aquat Sci 46:1958-1968

Raynie RC, Shaw RF (1994) Ichthyoplankton abundance along a recruitment corridor from offshore spawning to estuarine nursery ground. Estuar Coast Shelf Sci 39:421-450

Reiss CS, McConaugha JR (1998) Cross-frontal transport and distribution of ichthyoplankton associated with Chesapeake Bay plume dynamics. Cont Shelf Res 19:151-170

Rooker JR, Holt SA, Soto MA, Holt GJ (1998) Postsettlement

Editorial responsibility: Nick Tolimieri,

Seattle, Washington, USA patterns of habitat use by sciaenid fishes in subtropical seagrass meadows. Estuaries 21:318-327

Rowe PM, Epifanio CE (1994) Tidal stream transport of weakfish larvae in Delaware Bay, USA. Mar Ecol Prog Ser 110: 105-114

Schultz ET, Lwiza KMM, Fencil MC, Martin JM (2003) Mechanisms promoting upriver transport of larvae of two species in the Hudson River estuary. Mar Ecol Prog Ser 251: 263-277

Schultz ET, Young J, Martin JM, Lwiza KMM (2005) Tracking cohorts: analysis of migration in the early life stages of an estuarine fish. Estuaries 28:394-405

Shaw RF, Wiseman WJ, Turner RE, Rouse LJ, Condrey RE (1985) Transport of larval gulf menhaden Brevoortia tyrannus in continental shelf waters of western Louisiana: a hypothesis. Trans Am Fish Soc 114:452-460

Valle-Levinson A, Lwiza KMM (1997) Bathymetric influences on the lower Chesapeake Bay hydrography. J Mar Syst 12:221-236

> Valle-Levinson A, Li C, Royer TC, Atkinson LP (1998) Flow patterns at the Chesapeake Bay entrance. Cont Shelf Res 18:1157-1177

> Valle-Levinson A, Wong K, Bosley KT (2001) Observations of the wind-induced exchange at the entrance to Chesapeake Bay. J Mar Res 59:391-416

Warlen SM (1981) Age and growth of larvae and spawning time of Atlantic croaker in North Carolina. Proc Annu Conf Southeastern Assoc Fish Wildl Agencies 34:204-214

- Warlen SM (1992) Age, growth, and size distribution of larval Atlantic menhaden off North Carolina. Trans Am Fish Soc 121:588-598

- Warlen SM, Burke JS (1990) Immigration of larvae of fall/winter spawning marine fishes into a North Carolina estuary. Estuaries 13:453-461

Warlen SM, Chester AJ (1985) Age, growth, and distribution of larval spot, Leiostomus xanthurus, off North Carolina. Fish Bull (Wash DC) 83:587-599

Weinstein MP, Weiss SL, Hodson RG, Gerry LR (1980) Retention of three taxa of postlarval fishes in an intensively flushed tidal estuary, Cape Fear River, North Carolina. Fish Bull (Wash DC) 78:419-436

Werner FE, Blanton BO, Quinlan JA, Luettich RA (1999) Physical oceanography of the North Carolina continental shelf during the fall and winter seasons: implications for the transport of larval menhaden. Fish Oceanogr 8:7-21

- Wilk MB, Gnanadesikan R (1968) Probability plotting methods for the analysis of data. Biometrika 55:1-17

> Wong KC (1994) On the nature of transverse variability in a coastal plain estuary. J Geophys Res C Oceans 99: 14209-14222

Submitted: March 19, 2008; Accepted: November 25, 2008 Proofs received from author(s): February 26, 2009 